\title{
Dopamine Dysfunction in Borderline Personality Disorder: A Hypothesis
}

\author{
Robert O Friedel*, I \\ 'Department of Psychiatry, Medical College of Virginia/Virginia Commonwealth University, Richmond, VA, USA
}

\begin{abstract}
Research on the biological basis of borderline personality disorder (BPD) has focused primarily on the serotonin model of impulsive aggression. However, there is evidence that dopamine (DA) dysfunction may also be associated with BPD. Pertinent research and review articles, identified by Medline searches of relevant topics, books, references from bibliographies, and conference proceedings from 1975 to 2003, were reviewed. Evidence of DA dysfunction in BPD derives from the efficacy of traditional and atypical antipsychotic agents in BPD, and from provocative challenges with amphetamine and methylphenidate of subjects with the disorder. In addition, human and animal studies indicate that DA activity plays an important role in emotion information processing, impulse control, and cognition. The results of this review suggest that DA dysfunction is associated with three dimensions of BPD, that is, emotional dysregulation, impulsivity, and cognitive-perceptual impairment. The main limitation of this hypothesis is that the evidence reviewed is circumstantial. There is no study that directly demonstrates DA dysfunction in BPD. In addition, the therapeutic effects of antipsychotic agents observed in BPD may be mediated by non-DA mechanisms of action. If the stated hypothesis is correct, DA dysfunction in BPD may result from genetic, developmental, or environmental factors directly affecting specific DA pathways. Alternatively, DA dysfunction in BPD may be a compensatory response to alterations in the primary neural systems that control emotion, impulse control, and cognition, and that are mediated by the brain's main neurotransmitters, glutamate, and GABA, or in one or more other neuromodulatory pathways such as serotonin, acetylcholine, and norepinephrine.

Neuropsychopharmacology (2004) 29, 1029-1039, advance online publication, 24 March 2004; doi: I 0. I038/sj.npp. I 300424
\end{abstract}

Keywords: borderline personality disorder; neural basis; dopamine dysfunction; emotional dysregulation; impulsivity; cognitiveperceptual impairment

\section{INTRODUCTION}

BPD is characterized by: (1) emotional dysregulation; (2) impulsivity; (3) cognitive-perceptual impairment; and (4) disturbed relationships (American Psychiatric Association, 2001). Research on the biological basis of BPD has focused primarily on the relationships between impulsive aggression and serotonin (5-HT) dysfunction (Silk, 2000; Skodol et al, 2002). To a lesser degree, emotional dysregulation has been correlated with imbalances in cholinergic, noradrenergic, and GABAminergic neurotransmission (Skodol et al, 2002; Gurvits et al, 2000). A recent integration of the biological, psychosocial, and clinical findings in BPD does not mention

Presented as a Poster at the 4 Ist Annual Meeting of the American, College of Neuropsychopharmacology, San Juan, Puerto Rico, December 8-12, 2002.

* Correspondence: Dr RO Friedel, Department of Psychiatry, Medical College of Virginia/Virginia Commonwealth University, Nelson Clinic, Suite 200, 40 I North IIth Street, PO Box 980253, Richmond, VA 23298, USA, Tel: (804) 744 526I; 828 9452, Fax: (804) 744 4374, E-mail: rofriedel@aol.com

Received II December 2003; revised 26 January 2004; accepted 29 January 2004

Online publication: 4 February 2004 at http://www.acnp.org/citations/ Npp04020403560/default.pdf a potential role of DA dysfunction in the disorder (Schmahl et al, 2002).

This body of work leaves unexplained the efficacy of low doses of traditional neuroleptics and atypical antipsychotic agents in the treatment of patients with BPD (American Psychiatric Association, 2001; Table 1). The most commonly cited models of the mechanisms of action of antipsychotic agents in other mental disorders specify their capacity to block D2 (Kapur and Seeman, 2001), or D2 and 5-HT2 (Meltzer, 1989) receptors. In addition, this body of work does not consider evidence from animal and human studies that implicate DA activity in emotion information processing, impulse control, and cognition (Table 2). For example, DA modulates emotional responses to salient positive and negative events and arousalproducing stimuli (Everitt et al, 2000; Horvitz, 2000; Liberzon et al, 2003), and modulates working memory and cognition (Arnsten et al, 1994; Goldman-Rakic, 1996; Arnsten and Goldman-Rakic, 1998). There is evidence that CSF HVA levels may be related to impulsive behavior in patients with BPD (Coccaro, 1998; Chotai et al, 1998). Therefore, this review evaluated data relevant to the hypothesis that DA dysfunction in specific neural pathways is associated with one or more of the behavioral dimensions of BPD. 
Table I Summary of Effects of Traditional and Atypical Antipsychotic Agents in Placebo-Controlled Trials on Behavioral Dimensions of Borderline Personality Disorder

\begin{tabular}{|c|c|c|c|c|c|c|}
\hline \multirow[b]{2}{*}{ Agent studied } & \multirow[b]{2}{*}{$\begin{array}{l}\text { Mean } \\
\text { dose } \\
(\mathrm{mg})\end{array}$} & \multirow[b]{2}{*}{$\begin{array}{c}\text { Sample size } \\
\text { (AA/P) }\end{array}$} & \multirow[b]{2}{*}{$\begin{array}{c}\text { Study } \\
\text { period } \\
\text { (weeks) }\end{array}$} & \multicolumn{2}{|l|}{ Results } & \multirow[b]{2}{*}{ References } \\
\hline & & & & Drug-placebo differences & $\begin{array}{l}\text { Net effect } \\
\text { size }(\%)^{+}\end{array}$ & \\
\hline \multicolumn{7}{|c|}{ Emotional dysregulation } \\
\hline \multirow[t]{2}{*}{ Thiothixene } & $8.7 /$ day & $24 / 26$ & 12 & Phobic anxiety****** & IWS & Goldberg et al (1986) \\
\hline & & & & Obsessive-compulsive* & IWS & \\
\hline \multirow[t]{5}{*}{ Haloperidol } & 4.8/day & $28 / 28$ & 5 & Depression & & \\
\hline & & & & HAM-D-24* & 21 & Soloff et al $(1986,1989)$ \\
\hline & & & & Beck*** & 30 & \\
\hline & & & & HSCL-90* & 24 & \\
\hline & & & & Obsessive-compulsive* & 24 & \\
\hline \multirow[t]{3}{*}{ Trifluoperazine } & 7.8/day & $7 / / 5$ & 6 & Anxiety**** & 43 & Cowdry and Gardner (1988) \\
\hline & & & & Depression* & 36 & \\
\hline & & & & Anxiety**** & 35 & \\
\hline Olanzapine & 5.33/day & $19 / 9$ & 26 & Anxiety**** & 37 & Zanarini and Frankenberg (200I) \\
\hline \multicolumn{7}{|l|}{ Impulsivity } \\
\hline \multirow[t]{2}{*}{ Flupenthixol } & $20 \mathrm{im}$ & $14 / 16$ & 26 & Suicide attempts*** & 73 & Montgomery and Montgomery (1982) \\
\hline & q 4 weeks & & & & & \\
\hline \multirow[t]{5}{*}{ Haloperidol } & & & & Hostility*** & 45 & Soloff et al $(1986,1989)$ \\
\hline & & & & Hostile belligerence ${ }^{* * *}$ & 62 & \\
\hline & & & & Excitement* & 51 & \\
\hline & & & & Impulsivity patterns* & 67 & \\
\hline & & & & Impulse contro|*** & 19 & \\
\hline Trifluoperazine & & & & Suicidality**** & 40 & Cowdry and Gardner (1988) \\
\hline Olanzapine & & & & Anger/hostility* & NA & Zanarini and Frankenburg (200I) \\
\hline \multicolumn{7}{|c|}{ Cognitive perceptual impairment } \\
\hline \multirow[t]{3}{*}{ Thiothixene } & & & & Illusions****** & IWS & Goldberg et al (1986) \\
\hline & & & & Ideas of reference* & IWS & \\
\hline & & & & Psychoticism****** & IWS & \\
\hline \multirow[t]{3}{*}{ Haloperidol } & & & & Psychoticism* & 25 & Soloff et al $(1986,1989)$ \\
\hline & & & & Paranoid ideation***** & 45 & \\
\hline & & & & Paranoid projection* & 35 & \\
\hline Olanzapine & & & & Paranoia* & NA & Zanarini and Frankenburg (200I) \\
\hline \multicolumn{7}{|c|}{ Disturbed relationships } \\
\hline \multirow[t]{2}{*}{ Haloperidol } & & & & Global functioning* & 12 & Soloff et al $(1986,1989)$ \\
\hline & & & & Interpersonal sensitivity*** & 30 & \\
\hline Trifluoperazine & & & & Rejection sensitivity*** & 36 & Cowdry and Gardner (1988) \\
\hline Olanzapine & & & & Interpersonal sensitivity*** & NA & Zanarini and Frankenburg (200I) \\
\hline Haloperidol & $4 / d$ & $30 / 28$ & 5 & No drug effects detected & & Soloff et al (1993) \\
\hline
\end{tabular}

AA — antipsychotic agent; +_effect sizes were calculated from data presented; IWS —increases with severity; NA — data not available; * —less than or equal to .05: ***-less than or equal to 0.01 ; $* * *$ - less than or equal to 0.001 .

\section{METHODS}

Pertinent research and review articles, identified by Medline searches of relevant topics, books, references from bibliographies, and conference proceedings from 1975 to 2003 were reviewed.

\section{RESULTS}

Two main lines of evidence appear to implicate DA dysfunction in BPD: (1) pharmacological studies of patients and subjects with BPD; and (2) animal and human research 
Table 2 Summary of Evidence from Human and Animal Studies of Dopamine Dysfunction in the Behavioral Dimensions of Borderline Personality Disorder

\begin{tabular}{lll}
\hline Emotional dysregulation & Cognitive-perceptual impairment
\end{tabular}

Effects of amphetamine and methylphenidate in subjects with BPD (Schulz et al, 1985, 1988; Lucas et al, 1987)

Produce affective changes

Produce impulsivity

Produce psychosis and thought disturbance

\section{Other human and animal studies}

DA modulates responses to positive/negative rewards, salient events and arousal-producing stimuli (Everitt et al, 2000; Liberzon et al, 2003; Horvitz, 2000)

DA modulates emotional responses mediated by the amygdala-VTA-PFC circuits (Horvitz, 2000)

Stress alters DA activity in the amydala and PFC (Finlay and Zigmond, 1997; Doherty and Gratton, 1999)

DA modulates conditioned fear responses (Guarraci et al, 1999)
CSF HVA levels are related to impulsivity in BPD (Coccaro, 1998; Chotai et al, 1998); to self-injurious and violent behavior (Winchel and Stanley, 1991; Soderstrom et al, 200I)
DA receptor activity in the DLPFC modulates working memory and cognition (Arnsten et al, 1994; Goldman-Rakic, 1996; Arnsten and Goldman-Rakic, 1998)

PCP-induced cognitive impairment correlates with DA levels in the DLPFC (Jentsch et al, 1997)

DA modulates cognitive processes at NMDA receptors (Williams and Goldman-Rakic, 1995)
DA mediates aggression and attack in rats

(Wade et al, 2000; Vukhac et al, 200I)

DA stimulates impulsive behavior in rats (Harrison et al, 1997)
DI agonist dilhydrexidine enhances cognitive performance and stimulates Ach release in the PFC (Steele et al, 1997; Schneider et al, 1994)
Microdialysates of the PFC and the NAC suggest DA dysfunction is a risk factor for impulsivity (Van Erp and Miczek, 2000; Dalley et al, 2002)
DA dysfunction in the DLPFC is related to cognitive impairment in SCZ, SPD, and normal subjects (Goldberg et al, 2003; Siever et al, 2002)

DA — dopamine; CSF HVA — spinal fluid homovanillic acid; DLPFC—dorsolateral prefrontal cortex; PCP_phencylclidine; VTA — ventral tegmental area; PFC — prefrontal cortex; Ach — acetylcholine; NAC—nucleus accumbens; SCZ—-schizophrenia; SPD—schizotypal personality disorder.

implicating DA activity in emotion information processing, impulse control, and cognition.

\section{Pharmacological Evidence}

Placebo-controlled clinical trials of antipsychotic agents in $B P D$. Five of six placebo-controlled studies testing the efficacy of traditional and atypical antipsychotic agents in BPD have demonstrated significant drug effects (Table 1). As would be expected, the drugs tested consistently reduced the psychotic features of BPD. However, significant improvement was also noted in the areas of emotional dysregulation and impulsivity in four of the trials, respectively.

A number of open label trials of atypical antipsychotic agents in the treatment of BPD have been reported, including risperidone (Szigethy and Schulz, 1997; Rocca et al, 2002), clozapine (Frankenburg and Zanarini, 1993; Benedetti et al, 1998; Chengappa et al, 1999), and olanzapine (Schulz et al, 1999), uniformly suggesting efficacy in one or more of the dimensions of BPD.

Traditional and atypical antipsychotic agents are thought to act primarily through the blockade of D2 receptors (Kapur and Seeman, 2001). However, there is evidence that other mechanisms of action may also be important, such as 5-HT2 receptor blockade (Meltzer, 1989).

Amphetamine and methylphenidate challenge studies in $B P D$. Three placebo-controlled studies of agents that mainly challenge the DA system have been reported in subjects with BPD (Table 2). Amphetamine (AMPH) produced symptoms of psychosis in four of eight subjects with BPD, and a significant increase in global well being (Schulz et al, 1985). AMPH produced a greater increase in BPRS scores in subjects with BPD and schizotypal personality disorder (SPD) than in subjects with only BPD (Schulz et al, 1988). Subjects with BPD and SPD typically rated themselves worse after AMPH, while those with BPD alone usually reported themselves improved. Finally, in two of three subjects with BPD, methylphenidate caused affective symptoms, excitation, decreased impulse control, and cognitive disturbances similar to those experienced under stress (Lucas et al, 1987). It should be noted that although AMPH and methylphenidate are known to exert significant effects on CNS DA activity, they also affect other neurotransmitter systems, such as norepinephrine.

\section{The Effects of Dopamine in Human and Animal Studies}

DA effects on emotion. The extended amygdala plays a central role in the determination of positive and negative affects and the generation of species-specific responses (Davidson, 2001; Amaral, 2002; Liberzon et al, 2003). Information from sensory pathways and from stored experiences enters and is processed in the lateral and basal nuclei of the amygdala (Figure 1) (Pitkanen, 2000). The central nucleus of the amygdala provides the main efferents from the amygdala to the ventral tegmental area (VTA), the 
primary source of DA fibers to corticolimbic structures. Connections between the amygdala and the VTA directly link emotional states with CNS DA activity. Therefore, it is possible that reciprocal DA projections from the VTA to the amygdala (Figure 1) may not properly modulate DA effects on emotional reactivity in individuals with $\mathrm{BPD}$.

Motivation/reward: Dopamine activity in the nucleus accumbens (NAC) appears to play a major role in the positive reinforcement of conditioned, goal-directed behaviors and the experience of pleasure (Everitt et al, 2000), as well as salient non-reward events and arousal-producing environmental changes (Horvitz, 2000; Liberzon et al, 2003). The rich innervation of the NAC by the amygdala directly, and indirectly through the VTA (Figure 1) (Pitkanen, 2000), suggests that the amygdala exerts significant influence over the activity of these DA-modulated behavioral systems. A recent report indicates that cAMP-dependent protein kinase (PKA) activity in the amygdala can facilitate reward-related learning (Jentsch et al, 2002). PKA regulates DA- and cAMP-regulated phosphoprotein (DARPP-32) (Greengard, 2001). Dysphoric symptoms common in BPD may be related in part to DA dysfunction in these neural circuits.

Stress responses: The connections between the amygdala and the orbitomedial wall of the prefrontal cortex (PFC), including the anterior cingulate cortex (ACC), are critical in the conscious recognition, learning, and modulation of emotional responses to important external and internal stimuli (Figure 1) (Bechara et al, 2000; Davidson, 2002), and are modulated by DA activity (Rosenkranz and Grace, 2001). Stress induces release of DA in the NAC, but more strongly in the medial PFC (Finlay and Zigmond, 1997). This results in increased activation of local GABA transmission in the PFC that ultimately inhibits the DA response of the NAC to stress (Doherty and Gratton, 1999). Compared to controls, subjects with BPD demonstrate a decrease in amygdala volume (Rusch et al, 2003), an increase in amygdala activation bilaterally (Herpertz et al, 2001), and frontal and prefrontal hypermetabolism (Juengling et al, 2003). DA dysregulation in these neural circuits could result in an inappropriate balance of amygdala and prefrontal cortical activity in response to affect-inducing stimuli. A specific example of how this could operate in $\mathrm{BPD}$ is the conditioned fear response.

Conditioned fear responses: Fear-evoking stimuli processed in the amygdala are projected to subcortical structures to initiate rapid, organized, automatic conditioned fear responses (Figure 1) (LeDoux, 1996; Iversen et al, 2000). Sensory information is also transmitted to the cortical component of the conditioned fear neural system for processing, integration, and modulation of the rapid, conditioned responses initiated by the amygdala. Though slower than the amygdala component, the cortical component is more specific and brings conditioned emotional responses under a measure of conscious control through inhibitory feedback loops from the PFC to the amygdala, striatum, and critical brain stem nuclei. There is evidence

DOPAMINE PATHWAYS MODULATING THE NEURAL STRUCTURES AND CIRCUITS INVOLVED IN BEHAVIORAL DIMENSIONS OF BPD

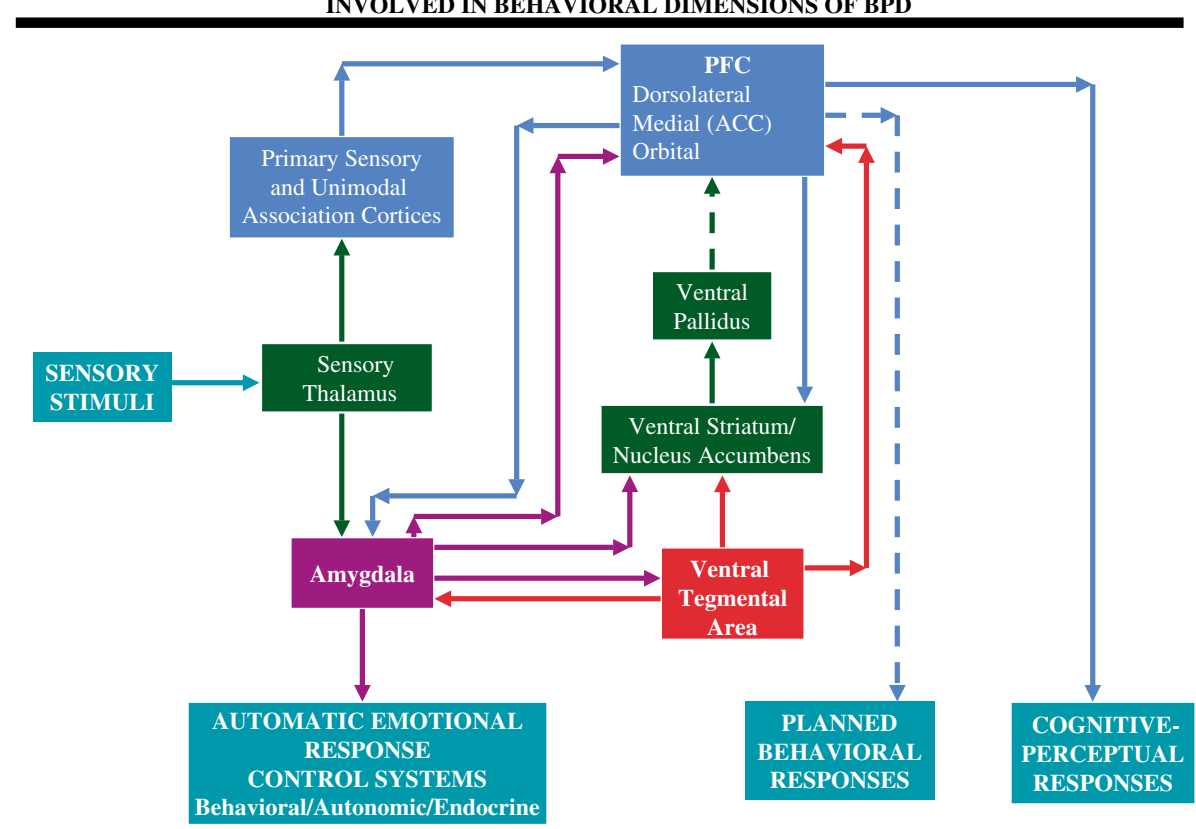

Figure I Sensory information is split at the thalamus and processed rapidly by the amygdala (AMG) to determine emotional valence. The AMG then initiates automatic, species-specific responses, signals the VTA to stimulate DA release when indicated, and projects information to the PFC, either directly or indirectly through the ventral striatum/nucleus accumbens (VS/NAC). The PFC also receives sensory stimuli directly from the thalamus for processing, resulting in a measure of cognitive control over emotional responses generated by subcortical systems via projections back to the AMG and the VS/NAC from the medial and orbital PFC, especially from the ACC. The dorsolateral PFC receives information from other PFC regions and from subcortical structures, including the VTA, and mediates the processes of working memory and components of executive function. Finally, integration of the functions of the different regions of the PFC may result in planned behavioral actions mediated by the pre-motor and motor cortices. DA pathways in red; - - - - - - , intermediate structures not represented in pathways. 
that DA activity in the amygdala is involved in fear conditioning (Guarraci et al, 1999). Dysregulated DA activity in the neural system regulating conditioned fear could result in the abnormal fear and anxiety responses prominent in BPD. In support of this is the finding that traditional and atypical antipsychotic agents significantly reduce anxiety in subjects with BPD (Table 1).

Anger: Evidence in support of critical roles of the extended amygdala and medial and lateral orbital PFC in the mediation and modulation of anger are derived from studies involving damage to these areas of the brain (Davidson et al, 2000), and from neuroimaging studies (Dougherty et al, 1999). The involvement of DA and 5-HT activity in the control of anger and aggression are discussed in the next section. In some studies, antipsychotic agents decrease anger in patients with BPD (Table 1).

Affect-driven memory: Strong connections between the amygdala and hippocampal formation establish part of the neuroanatomical framework for the processes of affectdriven memory formation and recall. As noted above, reward-related learning has been linked to activity in the amygdala of PKA, a modulator of DA signal transduction cascade pathways (Jentsch et al, 2002). Dysregulation of DA activity in the amygdala could account for the affect-related dissociative episodes observed in BPD.

Neuroimaging studies and emotion in BPD: There is evidence of structural and functional disturbances in the extended amygdala and related structures in subjects with BPD. Decreased volumes of the amygdala and hippocampus determined by MRI (Driessen et al, 2000; Rusch et al, 2003), and enhanced responses to emotionally aversive visual stimuli in the amygdala and medial and lateral orbital PFC measured by fMRI (Herpertz et al, 2001) have been reported in subjects with BPD. Facial expressions of emotion elicit significantly greater activation in the left amygdala in subjects with BPD compared with normal controls (Donegan et al, 2003). Levels of pessimistic attitudes correlate directly with 5-HT2 receptor binding potential in depressed subjects, but not in those with BPD (Meyer et al, 2003). This does not rule out 5-HT dysfunction in BPD mediated by other 5-HT receptors. These and other neuroimaging studies demonstrate abnormalities in the structure and function in brain regions that mediate emotion information processing, impulsivity, and cognition. However, there are no published neuroimaging studies that evaluate DA turnover or DA-binding potential in subjects with BPD. This issue will be addressed further in the discussion section of this review.

DA effects on impulse control. Impulsive aggression appears to be directly related to a deficiency in CNS 5-HT activity across a wide range of ages, psychiatric diagnoses, and normative personality types (Silk, 2000; Skodol et al, 2002). Recent evidence supporting the role of $5-\mathrm{HT}$ dysfunction in impulsive aggression in BPD has been provided by neuroimaging studies (Soloff et al, 2000; Leyton et al, 2001). However, the 5-HT hypothesis of impulsive aggression may be limited in scope (Oquendo and Mann,
2000). Four of six controlled trials of subjects with BPD treated with antipsychotic agents have shown a decrease in impulsive behavior (Table 1). In addition, there is evidence of a significant interaction between DA and 5-HT activity in impulsive behaviors.

CSF HVA and 5-HIAA levels in impulsive aggression and $B P D$ : Most studies have not demonstrated a correlation of CSF HVA and impulsive aggression (Brown et al, 1982; Virkkunen et al, 1994; Coccaro, 1998). However, when CSF HVA levels are adjusted for CSF 5-HIAA, Coccaro (1998) reports a significant inverse relationship between aggression and CSF HVA levels in subjects with personality disorders. The complex relationship between 5-HT and DA in impulsive behavior is further demonstrated in a recent study of the correlation between CSF 5-HIAA and HVA levels and scores on the Diagnostic Interview for Borderlines (DIB) in a large sample of patients with BPD (Chotai et al, 1998). Patients with an intermediate score on the impulse action subscale of the DIB had significantly higher levels of 5-HIAA and HVA than patients with low and with high scores. There is also evidence that patients with disorders other than BPD, who demonstrate severe selfinjurious behavior, have low CSF HVA levels and increased DA receptor sensitivity (Winchel and Stanley, 1991). In violent offenders, interpersonal and behavioral measures of psychopathy are related to high CSF HVA and low CSF 5-HIAA (Soderstrom et al, 2001).

DA dysfunction in alcoholism: Studies suggest that impulsivity in drug abuse results from decreased frontostriatal inhibitory responses to drugs that reinforce the DAmediated motivation/reward system (Modell et al, 1993; Kuikka et al, 1998; Jentsch and Taylor, 1999). VTA DA projection neurons are under inhibitory control by 5 -HT, mediated by 5-HT 2C receptors (Di Matteo et al, 2002). 5-HT $2 \mathrm{~A}$ and 5-HT 2C receptors modulate DA release induced by amphetamine and morphine, respectively, in the NAC and striatum, and 5-HT 2C receptors selectively modulate the impulse-flow-dependent release of DA (Porras et al, 2002).

Volkow and Fowler (2000) provide evidence that the orbital PFC is hypoactive relative to the levels of DA D2 receptors in the ventral striatum in addicted individuals during protracted withdrawal. However, during druginduced craving, the orbital PFC is hypermetabolic. This suggests that the high co-morbidity of drug abuse and BPD (Zanarini et al, 1998) may be partly related to an imbalance of DA activity in the ventral striatum and reciprocal orbital PFC inhibitory responses.

DA dysfunction and impulsive behaviors in animals: Recent evidence suggests that the NAC, well innervated by DA neurons, plays an important role in impulsive choice in rats (Cardinal et al, 2001). Aggressive and impulsive behaviors in rodents are modulated, in part, by DA activity at D1 and D2 receptors (Harrison et al, 1997; Vukhac et al, 2001). Dopamine-stimulated impulsive responses in rats are increased by central 5-HT depletion (Harrison et al, 1997). Microdialysates of the NAC and the medial PFC collected during behaviors measuring impulse control suggest that 
both DA and 5-HT dysfunction are risk factors of impulsivity (Van Erp and Miczek, 2000; Dalley et al, 2002).

\section{DA effects on cognition.}

$D A$ dysfunction in psychotic features of BPD: Psychotic features in subjects with BPD respond well to antipsychotic agents (Table 1), and are induced in some subjects with $\mathrm{BPD}$ by AMPH and methylphenidate provocative challenges (Table 2).

DA dysfunction in nonpsychotic cognitive symptoms of $B P D$ : Neuropsychological testing demonstrates nonpsychotic cognitive deficits in BPD, including impairments in reasoning, learning, memory, and executive functions (O'Leary, 2000). Neuroimaging studies in subjects with BPD indicate structural and functional changes in brain regions critical to cognitive activity, such as decreases in frontal lobe and hippocampal volumes (Driessen et al, 2000; Lyoo et al, 1998; Rusch et al, 2003), and changes in frontal lobe glucose metabolism (Goyer et al, 1994; De la Fuente et al, 1997; Juengling et al, 2003). Tebartz van Elst et al (2001) report a significant reduction of $\mathrm{N}$-acetylaspartate concentration (a proposed measure of neuronal integrity) in the dorsolateral prefrontal cortex (DLPFC) measured by ${ }^{1} \mathrm{H}-$ MRS in patients with BPD compared to controls. Memories of abandonment were associated with greater blood flow in the DLPFC bilaterally and in the right cuneus in women with BPD than in women without BPD (Schmahl et al, 2003). Evidence suggests that nonpsychotic cognitive disturbances in schizophrenia and normal subjects (Goldberg et al, 2003), and in schizotypal personality disorder (Siever et al, 2002), are due to hypodopaminergic activity in the PFC.

Animal studies provide the bulk of the evidence that cognitive function is modulated by DA activity in specific prefrontal cortical areas (Table 2). The DLPFC is important in the implementation of cognitive control, and the ACC in responding to incongruent stimuli, the monitoring of responses and initiating mid-course corrections in behavior (MacDonald et al, 2000; Shima and Tanji, 1998). D1 receptors predominate in the human cortical mantle (Hurd et al, 2001), and there is strong evidence that DA neurons projecting from the VTA to the DLPFC (Figure 1) serve to modulate working memory and cognition through their effects on D1 receptors (Arnsten et al, 1994; GoldmanRakic, 1996). The effect is bimodal. At low levels of DA activity, working memory is enhanced, while at moderate to high DA levels, working memory is impaired (Arnsten et al, 1994).

In monkeys, the performance of routine tasks is typically enhanced by stress, while even low to moderate levels of uncontrollable stress impair cognitive function through a hyperdopaminergic mechanism that is blocked by haloperidol, a mixed D1 and D2 receptor antagonist, and SCH 23390 (Arnsten and Goldman-Rakic, 1998). Cognitive impairment in monkeys can be produced by repeated treatment with phencyclidine (PCP) (Jentsch et al, 1997). The impairment produced by PCP, a glutamatergic antagonist, correlates significantly with a decrease in DA levels only in the DLPC and in the prelimbic cortex, and is reversed by clozapine.
Brembs et al, (2002) have demonstrated in Aplysia a cellular model of DA enhanced instrumental conditioning.

DA modulates cognitive processes in the PFC by gating glutamate activity at NMDA receptors (Williams and Goldman-Rakic, 1995). Glutamate upregulates DA D1 receptors by NMDA receptor activation (Scott et al, 2002). Any alteration in these mechanisms could cause an impairment of DA-modulated cognitive function (Jentsch et al, 1997). In addition, the D1 agonist dihydrexidine releases acetylcholine in the PFC and enhances cognitive performance in rats (Steele et al, 1997) and in monkeys (Schneider et al, 1994), effects blocked by SCH 23390. Of interest in this regard is the recent finding that atypical, but not traditional antipsychotic drugs increase cortical acetylcholine release in the PFC with no effect in the nucleus accumbens or striatum (Ichikawa et al, 2002).

\section{DISCUSSION}

\section{Pharmacological Evidence}

The strongest evidence supporting DA dysfunction in BPD derives from the therapeutic effects of antipsychotic agents on emotional dyscontrol, impulsivity, and cognitive impairment in controlled clinical trials (Table 1). There is evidence that disturbed relationships in BPD result from the social impairments caused by the other behavioral dimensions of the disorder (Koenigsberg et al, 2001). Effect sizes are clinically significant in all the three behavioral dimensions. They are comparable to those typically demonstrated in antidepressant clinical trials (Khan et al, 2000), and the percentage of trials showing efficacy ( $>80 \%$ ) is superior to results reported in standard antidepressant and anxiolytic clinical trials $(\sim 50 \%)$ (Khan et al, 2002). As these agents are thought to exert their therapeutic effects in other patient populations mainly by D2 (Kapur and Seeman, 2001), or by D2 and 5-HT2 (Meltzer, 1989) receptor blockade, it is reasonable to consider similar mechanisms of action in $\mathrm{BPD}$, thereby implicating DA dysfunction in these three dimensions of the disorder. Owing to the methodological limitations mainly involving sample size and diagnostic heterogeneity of subjects, the stimulant challenge studies (Table 2) add only a modest increment of support to the hypothesis.

\section{DA Effects on Emotion in Human and Animal Studies}

The neural circuits connecting the amygdala, NAC, and PFC areas associated with recognition and control of emotion (Pitkanen, 2000; Amaral, 2002) provide the neural pathways by which DA dysfunction could play a significant role in the dimension of emotional dysregulation in BPD. This proposal is supported by the relationships of DA activity in the extended amygdala, NAC, and PFC to fear conditioning (Guarraci et al, 1999), motivation, reward, and stress (Horvitz, 2000; Finlay and Zigmond, 1997), and of DA and 5-HT activity in these structures in anger (Swann, 2003). Of interest is the recent report by Jentsch et al (2002) that cAMP-dependent protein kinase (PKA) activity in the amygdala can facilitate reward-related learning. PKA regulates the activity of DA- and cAMPregulated phosphoprotein (DARPP-32) (Greengard, 2001). 
These findings raise the possibility that DA dysfunction affecting the motivation/reward neural circuits may be related to impaired motivation and positive behavioral reinforcement in BPD, and suggest a biochemical mechanism of action.

Finally, neuroimaging studies demonstrate structural abnormalities in the amygdala (Driessen et al, 2000, Schmahl et al, 2003), and enhanced responses to emotionally aversive stimuli in the amygdala and medial and lateral orbital PFC in subjects with BPD (Herpertz et al, 2001; Donegan et al, 2003). In sum, the studies of subjects with BPD and the animal and human studies on the neural basis of emotion and reward suggest a link between the pathophysiology of the neural circuits affected in BPD to DA dysfunction. However, more definitive studies establishing this relationship are indicated as noted below.

\section{DA Effects on Impulsivity in Human and Animal Studies}

There is strong evidence of 5-HT dysfunction in impulsive aggression across a broad population range including BPD (Silk, 2000; Skodol et al, 2002). Neuroimaging studies consistently demonstrate a decrease in 5-HT function in the medial PFC of subjects with BPD, which correlates with the degree of impulsive aggression (Soloff et al, 2000; Leyton et al, 2001). However, the evidence from human and animal studies reviewed above suggests a reciprocal interaction of DA hyperactivity and 5-HT hypoactivity in this dimension of BPD (Table 2). A possible biochemical mechanism of this interaction will be discussed below.

\section{DA Effects on Cognition in Human and Animal Studies}

The most robust evidence of DA dysfunction affecting cognition in BPD is the effect of antipsychotic agents on psychotic features of the disorder (Table 1). Current hypotheses and evidence suggesting the roles of DA (Kapur and Seeman, 2001), and DA and 5-HT (Meltzer, 1989) dysfunction in psychotic symptoms support this contention. Other evidence cited (Table 2) suggest that DA dysfunction may also be involved in more subtle cognitive disturbances manifested by subjects with BPD (O'Leary, 2000), consistent with similar findings in schizophrenia (Goldberg et al, 2003) and SPD (Siever et al, 2002).

Numerous animal studies also indicate that DA activity plays a significant role in cognitive processes (Table 2), and present sites in DA signal transduction cascades as potential loci of genetic vulnerability in BPD. However, there are no published studies evaluating DA activity and cognitive function, including working memory, in subjects with BPD. Such studies in schizophrenia (Goldberg et al, 2003) and in schizotypal personality disorder (Siever et al, 2002) have demonstrated a correlation between DA dysfunction and cognitive impairment. Similar studies seem warranted in BPD.

\section{Mechanisms of Action}

It is now generally accepted that the prefrontal and temporal regions of the brain operate as part of architectonically and functionally discrete, parallel closed loop circuits that link cortical regions with subcortical structures, such as the basal ganglia, thalamus, extended amygdala, and hippocampus (Masterman and Cummings, 1997; Trimble et al, 1997). These circuits interface with one another in a manner referred to as parallel distributed processing to produce neural systems with specific functions (Trimble et al, 1997). These neural systems are mediated by glutamate and GABA, the primary stimulatory and inhibitory brain neurotransmitters, and are modulated by DA, 5-HT, and other neuromodulators. Recent studies suggest the involvement of DA activity in some of the circuits that are associated with the behavioral dimensions of BPD. For example, it has been suggested that the Aplysia cellular model of DA-enhanced instrumental conditioning recently demonstrated by Brembs et al (2002) may be conserved in higher animal forms, and may provide the basis for the learning of reward-seeking behaviors mediated by DA in the NAC (Rankin, 2002).

At the molecular level, the facilitation of reward-based learning by PKA activity in the amygdala may operate by the regulation of DARPP-32 phosphorylation (Jentsch et al, 2002). A recent report indicates that, in addition to DA, 5HT also regulates DARPP-32 phosphorylation (Svenningsson et al, 2002a), an effect modified by fluoxetine (Svenningsson et al, 2002b). Some of the effects of diverse psychotomimetics on DA, 5-HT, and glutamate activity in humans and in animals appear to be mediated by the DARPP-32 signal transduction pathway (Svenningsson et al, 2003). This mechanism may also mediate a portion of the reciprocal interactions of DA and 5-HT on the specific behavioral dimensions of BPD.

If DA dysfunction is associated with BPD, it may be the result of genetic, developmental, or environmental factors directly affecting specific DA pathways. Alternatively, DA dysfunction in BPD may be a compensatory response to the effects of these factors either on the primary neural systems that control emotion, impulse regulation, and cognition that are mediated by the main neurotransmitters of the brain, glutamate, and GABA, or on one or more of the other neurotransmitter pathways that modulate activity in these neural systems such as serotonin, acetylcholine, and norepinephrine.

\section{Implications}

The data presented in this review are consistent with the stated hypothesis that DA dysfunction plays an important role in three behavioral dimensions of BPD. This hypothesis has at least three heuristic implications. First, it broadens the conceptual framework for investigations of the neural mechanisms that operate as risk factors for BPD. More specifically, the data suggest complex interactions of the neural systems that mediate these behavioral dimensions, as shown in Figure 1. For example, in the dimension of emotional dysregulation, hyper-reactive response to salient stimuli by the amygdala may result in enhanced conditioned fear responses in individuals with BPD. These enhanced responses could result from an increase in DA activity in the amygdala (Guarraci et al, 1999) that is inadequately modulated by medial prefrontal cortical inhibition (Rosenkranz and Grace, 2001). 
At this point, it would be tempting to generate a general hypothesis of hyperdopaminergic and hyposerotonergic activity in those neural circuits mediating emotion information processing, impulsivity, and cognitive-perceptual activity in individuals with BPD. However, the high degree of architectonic specificity, the heterogeneity of neurotransmitter receptors and signal transduction cascade pathways in the circuits, the compensatory capacity of the circuits, and the meager amount of data from all sources require restraint from doing so. These factors may be responsible for the failure to find clear relationships between CSF DA and 5-HT metabolites in subjects with BPD (Chotai et al, 1998; Coccaro, 1998). If only a few specific DA and 5-HT pathways are involved in modulating the circuitry responsible for the behaviors present in BPD, we are searching for very small changes in CSF metabolites among a large amount of background data.

In addition, it is not proposed that DA dysfunction is involved in all symptoms in each of the three dimensions of BPD focused on in this review. For example, the identity disturbance commonly observed in individuals with BPD may be regarded as a cognitive-perceptual impairment. However, I know of no data that relates this disturbance to DA dysfunction in any subject population.

The hypothesis does suggest areas of investigation of the nature of BPD that have not been pursued. To date, there are no reported studies that utilize a PET tracer that images both striatal and extrastriatal behavior-related DA binding in subjects with BPD and in controls. For example, relationships between DA activity and cognitive dysfunction have been demonstrated in both schizophrenia (Goldberg et al, 2003) and in schizotypal personality disorder (Siever et al, 2002). Similar studies appear to be warranted in BPD in order to determine the presence of DA dysfunction in $B P D$ and the specific cognitive and other behavioral impairments of BPD related to this dysfunction.

AMPH-induced changes in ${ }^{11} \mathrm{C}$-raclopride DA D2/D3 binding potential (BP) observed in the anterior ventral striatum, but not in the dorsal caudate, correlate inversely with euphoria scale changes in normal subjects (Drevets et al, 2001). Yasuno et al (2001) have demonstrated that the $\mathrm{BP}$ in the amygdala of the extrastriatal D2 radiotracer ${ }^{11} \mathrm{C}$ FLB 457 correlates significantly with personality trait scores of harm avoidance, a personality trait related to BPD (Svrakic et al, 1993). These studies suggest that studies utilizing analogous methodologies in subjects with BPD may provide tests of the proposed relationships between DA dysfunction and symptoms of BPD.

Second, the hypothesis suggests new directions in the selection of candidate genes for analysis of the genetic basis of BPD, and for genetic manipulation in the development of animal models of the disorder. Even if DA dysfunction were demonstrated in neuroimaging studies, it would not necessarily indicate primary defects in DA pathways related to the behavioral dimensions of BPD. Abnormalities in DA function in BPD demonstrated by such studies might reflect compensatory changes to basic flaws in other neurotransmitter systems. Genetic and other studies would be required to provide direct evidence of dysfunction in DA transporter and DA signal transduction cascade pathways.

The hypothesis does not consider DA dysfunction to be the only risk factor for BPD. There is evidence that oligogenic, developmental, and environmental risk factors operate and interact to produce the full phenotypic expression of BPD (Silk, 2000; Skodol et al, 2002). Consequently, it would seem likely that disturbances at other chemical nodal points in the neural systems mediating the dimensions of BPD, such as the glutamate, GABA, and 5-HT signal transduction cascade pathways, may serve as additional risk factors for the disorder.

Third, the hypothesis provides a scientific rationale for the expanded study and use of antipsychotic agents in patients with BPD. The first controlled study of an atypical antipsychotic agent in subjects with BPD has recently been reported (Table 1) (Zanarini and Frankenburg, 2001).

\section{Limitations}

The main limitation of the proposed hypothesis is that the evidence reviewed is circumstantial. As noted, there are no studies that directly demonstrate DA dysfunction in subjects with BPD. The therapeutic effects of antipsychotic agents in BPD may operate through non-DA pathways, or result from nonspecific decreases in symptom severity not related directly to DA mechanisms. However, the two leading models of the mechanism of action of antipsychotic agents both involve the effect of these agents on DA activity (Meltzer, 1989; Kapur and Seeman, 2001), and a molecular mechanism of action of these agents through a signaling pathway common to DA, 5-HT and glutamate has recently been proposed (Svenningsson et al, 2003). Also, I know of no existing, credible models of non-DA mediated reductions in symptom severity by antipsychotic agents in any mental disorder. Finally, it may be argued that the hypothesis attempts to attribute too many of the behavioral dimensions of BPD to a single neurotransmitter disturbance. This issue has been addressed in the above sections on mechanisms of action and implications. Ultimately, genetic studies, behavior-related neuroimaging studies evaluating CNS DA function, and other research strategies in subjects with BPD and in animal models of the disorder, will be required to test the validity of the hypothesis.

\section{ACKNOWLEDGEMENTS}

I am grateful to Drs Hagop S Akiskal, Kenneth S Kendler, and Elliott Richelson for their review of an earlier version of the manuscript, and their thoughtful comments and helpful suggestions. The content of this article does not necessarily represent their views. I receive financial support to conduct evaluations of antipsychotic agents in the treatment of subjects with borderline personality disorder from Janssen Pharmaceutica, Eli Lilly and Co. and BristolMyers Squibb Co.

\section{REFERENCES}

Amaral DG (2002). The primate amygdala and the neurobiology of social behavior: implications for understanding social anxiety. Biol Psychiatry 51: 11-17.

American Psychiatric Association (2001). Practice guideline for the treatment of patients with borderline personality disorder. Am J Psychiatry 158(Suppl): 1-52. 
Arnsten AFT, Cai JX, Murphy BL, Goldman-Rakic PS (1994). Dopamine D1 receptor mechanisms in the cognitive performance of young adult and aged monkeys. Psychopharmacology 116: $143-151$.

Arnsten AFT, Goldman-Rakic PS (1998). Noise stress impairs prefrontal cortical cognitive function in monkeys. Arch Gen Psychiatry 55: 362-368.

Bechara A, Damascio H, Damascio AR (2000). Emotion, decisionmaking and the orbitofrontal cortex. Cereb Cortex 10: 295-307.

Benedetti F, Sforzini L, Colombo C, Maffei C, Smeraldi E (1998). Low-dose clozapine in acute and continuation treatment of severe borderline personality disorder. J Clin Psychiatry 59: 103-107.

Brembs B, Lorenzetti FD, Reyes FD, Baxter DA, Byrne JH (2002). Operant reward learning in Aplsia: neuronal correlates and mechanisms. Science 296: 1706-1709.

Brown GL, Ebert MH, Goyer PF, Jimerson DC, Klein WJ, Bunney WE et al (1982). Aggression, suicide, and serotonin relationships to CSF to CSGF amine metabolites. Am J Psychiatry 139: 741-746.

Cardinal RN, Pennicott DR, Sugathapala CL, Robbins TW, Everitt BJ (2001). Impulsive choice induced in rats by lesions of the nucleus accumbens core. Science 292: 2499-2501.

Chengappa KNR, Ebeling T, Kang JS, Levine J, Parepally H (1999). Clozapine reduces severe self-mutilation and aggression in psychotic patients with borderline personality disorder. J Clin Psychiatry 60: 477-484.

Chotai J, Kullgren G, Asberg M (1998). CSF monoamine metabolites in relation to the diagnostic interview for borderline patients (DIB). Neuropsychobiology 38: 207-212.

Coccaro E (1998). Neurotransmitter function in personality disorders. In: Silk KR (ed). Biology of Personality Disorders. American Psychiatric Press: Washington, DC. pp 1-25.

Cowdry RW, Gardner DL (1988). Pharmacotherapy of borderline personality disorder. Arch Gen Psychiatry 45: 111-119.

Dalley JW, Theobald DE, Eagle DM, Passetti F, Robbins TW (2002). Deficits in impulse control associated with tonically elevated serotonergic function in rat prefrontal cortex. Neuropsychopharmacology 26: 716-728.

Davidson RJ (2001). Toward a biology of personality and emotion. Ann NY Acad Sci 935: 191-207.

Davidson RJ (2002). Anxiety and affective style: role of prefrontal cortex and amygdala. Biol Psychiatry 51: 68-80.

Davidson RJ, Putnam KM, Larson CL (2000). Dysfunction in the neural circuitry of emotion regulation - a possible prelude to violence. Science 289: 591-594.

De la Fuente JM, Goldman S, Stanus E, Vizuete C, Morlan I, Bobes J et al (1997). Brain glucose metabolism in borderline personality disorder. J Psychiatr Res 31: 531-541.

Di Matteo V, Cacchio M, Di Giulio C, Di Giovanni G, Esposito E (2002). Biochemical evidence that the atypical antipsychotic drugs clozapine and risperidone block 5-HT 2C receptors in vivo. Pharmacol Biochem Behav 71: 607-613.

Doherty MD, Gratton A (1999). Effects of medial prefrontal cortical injections of GABA receptor agonists and antagonists on the local and nucleus accumbens responses to stress. Synapse 15: 288-300.

Donegan NH, Sanislow CA, Blumberg HP, Fulbright RK, Lacadie C, Skudlarski $\mathrm{P}$ et al (2003). Amygdala hyperreactivity in borderline personality disorder: implications for emotional dysregulation. Biol Psychiatry 54: 1284-1293.

Dougherty DD, Shin LM, Alpert NM, Pitman RK, Orr SP, Lasko M et al (1999). Anger in healthy men: a PET study using scriptdriven imagery. Biol Psychiatry 46: 466-472.

Drevets WC, Guitier C, Price JC, Kupfer DJ, Kinahan PE, Grace AA et al (2001). Amphetamine-induced dopamine release in human ventral striatum correlates with euphoria. Biol Psychiatry 49: 81-96.
Driessen M, Hermann J, Stahl K, Zwann M, Meier S, Hill A et al (2000). Magnetic resonance imaging volumes of the hippocampus and the amygdala in women with borderline personality disorder and early traumatization. Arch Gen Psychiatry 57: $1115-1122$.

Everitt BJ, Cardinal RN, Hall J, Parkinson JA, Robbins TW (2000). Differential involvement of amygdala subsystems in appetitive conditioning and drug addiction. In: Aggleton JP (ed). The Amygdala: A Functional Analysis. Oxford University: New York. pp 353-390.

Finlay JM, Zigmond MJ (1997). The effects of stress on central dopaminergic neurons: possible clinical implications. Neurochem Res 22: 1387-1394.

Frankenburg FR, Zanarini MC (1993). Clozapine treatment of borderline patients: a preliminary study. Compr Psychiatry 34: 402-405.

Goldberg SC, Schulz SC, Schulz PM, Resnick RJ, Hamer RM, Friedel RO (1986). Borderline and schizotypal personality disorders treated with low-dose thiothixene vs placebo. Arch Gen Psychiatry 43: 680-686.

Goldberg TE, Egan MF, Gscheidle T, Coppola R, Weickert T, Kolachana BS et al (2003). Executive sub processes in working memory: relationship to catechol-o-methyltransferase val158met genotype and schizophrenia. Arch Gen Psychiatry 60: 889-896.

Goldman-Rakic PS (1996). Regional and cellular fractionation of working memory. Proc Nat Acad Sci USA 93: 13473-13480.

Goyer PF, Andreason PJ, Semple WE, Clayton AH, King AC, Compton-Toth BA et al (1994). Positron-emission tomography and personality disorders. Neuropsychopharmacology 10: 21-28.

Greengard P (2001). The neurobiology of dopamine signaling. Biosci Rep 21: 247-269.

Guarraci FA, Frohardt RJ, Kapp BS (1999). Amygdaloid D1 dopamine receptor involvement in Pavlovian fear conditioning. Brain Res 827: 28-40.

Gurvits IG, Koenigsberg HW, Siever LJ (2000). Neurotransmitter dysfunction in patients with borderline personality disorder. Psychiatric Clin North Am 23: 27-40.

Harrison AA, Everitt BJ, Robbins TW (1997). Central 5-HT depletion enhances impulsive responding without affecting the accuracy of attentional performance: interactions with dopaminergic mechanisms. Psychopharmacology 133: 329-342.

Herpertz SC, Dietrich TM, Wenning B, Krings T, Erberich SG, Willmes $\mathrm{K}$ et al (2001). Evidence of abnormal amygdala functioning in borderline personality disorder: a functional MRI study. Biol Psychiatry 50: 292-298.

Horvitz JC (2000). Mesolimbocortical and nigrostriatal dopamine responses to salient non-reward events. Neuroscience 4: 651-656.

Hurd YL, Suzuki M, Sedvall GC (2001). D1 and D2 dopamine receptor mRNA expression in whole hemisphere sections of the human brain. J Chem Neuroanat 22: 127-137.

Ichikawa J, Dai J, O'Laughlin IA, Fowler WL, Meltzer HY (2002). Atypical, but not typical, antipsychotic drugs increase cortical acetylcholine release without an effect in the nucleus accumbens or striatum. Neuropsychopharmacology 26: 325-339.

Iversen S, Kupferman I, Kandel ER (2000). Emotional states and feelings. In: Kandel KR, Schwartz JH, Jessell TM (eds). The Principles of Neural Science. McGraw-Hill: New York. pp 982-997.

Jentsch JD, Olausson P, Nestler EJ, Taylor JR (2002). Stimulation of protein kinase activity in the rat amygdala enhances rewardrelated learning. Biol Psychiatry 52: 111-118.

Jentsch JD, Redmond Jr DE, Elsworth JR, Youngren KD, Roth RH (1997). Enduring cognitive deficits and cortical dopamine dysfunction in monkeys after long-term administration of phencyclidine. Science 277: 953-955.

Jentsch JD, Taylor JR (1999). Impulsivity resulting from frontostriatal dysfunction in drug abuse: implications for the control of 
behavior by reward-related stimuli. Psychopharmacology 146: 373-390.

Juengling FD, Schmahl C, Hesslinger B, Ebert D, Bremner JD, Gostomzyk J et al (2003). Positron emission tomography in female patients with borderline personality disorder. J Psychiatr Res 37: 109-115.

Kapur S, Seeman P (2001). Does fast dissociation from the dopamine D2 receptors explain atypical antipsychotic action-a new hypothesis. Am J Psychiatry 158: 360-369.

Khan A, Khan S, Brown WA (2002). Are placebo controls necessary to test new antidepressants and anxiolytics? Int J Neuropsychopharmacol 5: 193-197.

Khan A, Warner HA, Brown WA (2000). Symptom reduction and suicide risk in patients treated with placebo in antidepressant clinical trials: an analysis of the Food and Drug Administration database. Arch Gen Psychiatry 57: 311-317.

Koenigsberg HW, Harvey PD, Mitropolou V, New AS, Goodman M, Silverman J et al (2001). Are the interpersonal and identity disturbances in the borderline personality disorder criteria linked to the traits of affective instability and impulsivity? J Personal Disord 15: 358-370.

Kuikka JT, Tiihonen J, Bergstrom KA, Karhu J, Rasanen P, Eronen M (1998). Abnormal structure of human striatal dopamine reuptake sites in habitually violent alcoholic offenders: a fractal analysis. Neurosci Lett 253: 195-197.

LeDoux J (1996). The Emotional Brain: The Mysterious Underpinnings of Emotional Life. Touchstone: New York. pp 157-165.

Leyton M, Okazawa H, Diksic M, Paris J, Ross P, Mzengeza S et al (2001). Brain regional alpha-(11C)methyl-L-tryptophan trapping in impulsive subjects with borderline personality disorder. Am J Psychiatry 158: 775-782.

Liberzon I, Phan KL, Decker LR, Taylor SF (2003). Extended amygdala and emotional salience: a PET activation study of positive and negative affect. Neuropsychopharmacology 28 726-733.

Lucas PB, Gardner DL, Wolkowitz OM, Cowdry RW (1987). Dysphoria associated with methylphenidate infusion in borderline personality disorder. Am J Psychiatry 144: 1577-1579.

Lyoo K, Han MH, Cho DY (1998). A brain MRI study in subjects with borderline personality disorder. J Affect Dis 50: 235-243.

MacDonald III AW, Cohen JD, Stenger VA, Carter CS (2000). Dissociating the role of the dorsolateral prefrontal cortex in cognitive control. Science 288: 1835-1838.

Masterman DL, Cummings JL (1997). Frontal-subcortical circuits: the anatomic basis of executive, social and motivated behavior. J Psychopharmacol 11: 107-114.

Meltzer HY (1989). Clinical studies in the mechanism of action of clozapine: the dopamine serotonin hypothesis of schizophrenia. Psychopharmacology 99: 518-527.

Meyer JH, McMain S, Kennedy SH, Korman L, Brown GM, Da Silva JN et al (2003). Dysfunctional attitudes and 5-HT2 receptors during depression and self-harm. Am J Psychiatry 160: 90-99.

Modell JG, Mountz JM, Blazer FB, Lee JY (1993). Effect of haloperidol on measures of craving and impaired control in alcoholic subjects. Alcoholism 17: 234-240.

Montgomery SA, Montgomery D (1982). Pharmacological prevention of suicidal behavior. J Affect Disord 4: 291-298.

O'Leary KM (2000). Borderline personality disorder; neuropsychological testing results. Psychiatric Clin North Am 23: 41-46.

Oquendo MA, Mann JJ (2000). The biology of impulsivity and suicidality. Psychiatr Clin North Am 23: 11-25.

Pitkanen A (2000). Connectivity of the rat amygdaloid complex. In: Aggleton JP (ed). The Amygdala: A Functional Analysis. Oxford University: New York. pp 31-115.

Porras G, Di Matteo V, Fracasso C, Lucas G, De Deurwaerdere P, Caccia $\mathrm{S}$ et al (2002). 5-HT 2A and 5-HT 2C receptor subtypes modulate dopamine release induced in vivo by amphetamine and morphine in both the rat nucleus and striatum. Neuropsychopharmacology 26: 311-324.

Rankin CH (2002). A bite to remember. Science 296: 1624-1625.

Rocca P, Marchiaro L, Cocuzza E, Bogetto F (2002). Treatment of borderline personality disorder with risperidone. J Clin Psychiatry 63: 241-244.

Rosenkranz JA, Grace AA (2001). Dopamine attenuates prefrontal cortical suppression of sensory inputs to the basolateral amygdala of rats. J Neurosci 21: 4090-4103.

Rusch N, van Elst LT, Ludaescher P, Wilke M, Huppertz HJ, Thiel $\mathrm{T}$ et al (2003). A voxil-based morphometric MRI study in female patients with borderline personality disorder. Neuroimage 20: 385-392.

Schmahl CG, Elzinga BM, Vermetten E, Sanislow C, McGlashan TH, Bremner JD (2003). Neural correlates of memories of abandonment in women with and without borderline personality disorder. Biol Psychiatry 15: 142-151.

Schmahl CG, McGlashan TH, Bremner JD (2002). Neurobiological correlates of borderline disorder. Psychopharmacol Bull 36: 69-87.

Schneider JS, Sun Z-Q, Roeltgen DP (1994). Effects of dihydrexidine, a full dopamine D-1 receptor agonist, on delayed response performance in chronic low dose MPTP-treated monkeys. Brain Res 663: 140-144.

Schulz SC, Camlin KL, Berry SA, Jesberger JA (1999). Olanzapine safety and efficacy in patients with borderline personality disorder and comorbid dysthymia. Biol Psychiatry 46: 1429-1435.

Schulz SC, Cornelius J, Schulz PM, Soloff PH (1988). The amphetamine challenge test in patients with borderline disorder. Am J Psychiatry 145: 809-814.

Schulz SC, Schulz PM, Dommisse C, Hamer RM, Blackard WG, Narasimhachari $\mathrm{N}$ et al (1985). Amphetamine response in borderline patients. Psychiatry Res 15: 97-108.

Scott L, Kruse MS, Forssberg H, Brismar H, Greengard P, Aperia A (2002). Selective up-regulation of dopamine D1 receptors in dendritic spines by NMDA receptor activation. Proc Natl Acad Sci USA 99: 1661-1664.

Shima K, Tanji J (1998). Role for cingulate motor area cells in voluntary movement selection based on reward. Science 282: $1335-1338$.

Siever LJ, Koenigsberg HW, Harvey P, Mitropoulou V, Laruelle M, Abi-Dargham A et al (2002). Cognitive and brain function in schizotypal personality disorder. Schizophr Res 54: 157-167.

Silk KR (2000). Borderline personality disorder: overview of biological factors. Psychiatric Clin North Am 23: 61-76.

Skodol AE, Siever LJ, Livesley WJ, Gunderson JG, Pfohl B, Widiger TA (2002). The borderline diagnosis II: biology, genetics, and clinical course. Biol Psychiatry 51: 951-963.

Soderstrom H, Blennow K, Manhem A, Forsman A (2001). CSF studies in violent offenders. I. 5-HIAA as a negative and HVA as a positive predictor of psychopathy. J Neural Transm 108: 869-878.

Soloff PH, Cornelius J, George A, Nathan S, Perel JM, Ulrich RF (1993). Efficacy of phenelzine and haloperidol in borderline personality disorder. Arch Gen Psychiatry 50: 377-385.

Soloff PH, George A, Nathan RS, Schulz PM, Cornelius JR, Herring J et al (1989). Amitriptyline versus haloperidol in borderlines: final outcomes and predictors of response. J Clin Psychopharmacol 9: 238-246.

Soloff PH, George A, Nathan RS, Schulz PM, Ulrich RF, Perel J (1986). Progress in pharmacotherapy of borderline disorders. Arch Gen Psychiatry 43: 691-697.

Soloff PH, Meltzer CC, Greer PJ, Constantine D, Kelly TM (2000). A fenfluramine-activated FDG-PET study of borderline personality disorder. Biol Psychiatry 47: 540-547.

Steele TD, Hodges Jr DB, Levesque TR, Locke KW (1997). D1 agonist dihydrexidine releases acetylcholine and improves 
cognitive performance in rats. Pharmacol Biochem Behav 58: 477-483.

Svenningsson P, Tzavara ET, Carruthers R, Rachleff I, Wattler S, Nehls McKenzie DL et al (2003). Diverse psychotomimetics act through a common signaling pathway. Science 302: 1412-1415.

Svenningsson P, Tzavara ET, Liu R, Fienberg AA, Nomikos GG, Greengard P (2002a). DARPP-32 mediates serotonergic neurotransmission in the forebrain. Proc Natl Acad Sci USA 99: 3188-3193.

Svenningsson P, Tzavara ET, Witkin JM, Fienberg AA, Nomikos GG, Greengard P (2002b). Involvement of striatal and extrastriatal DARPP-32 in biochemical and behavioral effects of fluoxetine (Prozac). Proc Natl Acad Sci USA 99: 3182-3187.

Svrakic DM, Whitehead C, Przybeck TR, Cloninger CR (1993). Differential diagnosis of personality disorders by the sevenfactor model of temperament and character. Arch Gen Psychiatry 50: 991-999.

Swann AC (2003). Neuroreceptor mechanisms of aggression and its treatment. J Clin Psychiatry 64(Suppl 4): 26-35.

Szigethy EM, Schulz SC (1997). Risperidone in comorbid borderline personality disorder and dysthymia. J Clin Psychopharmacol 17: 326-327.

Tebartz van Elst L, Theil T, Hesslinger B, Lieb K, Bohus M, Henning J et al (2001). Subtle prefrontal neuropathology in a pilot magnetic resonance spectroscopy study in patients with borderline personality disorder. J Neuropsychiatry Clin Neurosci 13: 511-514.

Trimble MR, Mendez MF, Cummings JL (1997). Neuropsychiatric symptoms from the temporolimbic lobes. J Neuropsychiatry Clin Neurosci 9: 429-438.

Van Erp AM, Miczek KA (2000). Aggressive behavior, increased accumbal dopamine, and decreased cortical serotonin in rats. J Neurosci 20: 9320-9325.
Virkkunen M, Rawlings R, Tokola R, Poland RE, Guidotti A, Nemeroff C et al (1994). CSF biochemistries, glucose metabolism, and diurnal activity rhythms in alcoholic, violent offenders, fire setters, and healthy volunteers. Arch Gen Psychiatry 51: $20-27$.

Volkow ND, Fowler JS (2000). Addiction, a disease of compulsion and drive: involvement of the orbitofrontal cortex. Cereb Cortex 10: $318-325$.

Vukhac KL, Sankoorikal EB, Wang Y (2001). Dopamine D2L receptor- and age-related reduction in offensive aggression. Neuroreport 12: 1035-1038.

Wade TR, de Wit H, Richards JB (2000). Effects of dopaminergic drugs on delayed reward as a measure of impulsive behavior in rats. Psychopharmacology 150: 90-101.

Williams GV, Goldman-Rakic PS (1995). Modulation of memory fields by dopamine D1 receptors in prefrontal cortex. Nature 376: $572-575$.

Winchel RM, Stanley M (1991). Self-injurious behavior: a review of the behavior and biology of self-mutilation. Am J Psychiatry 148: 306-317.

Yasuno F, Suhara T, Sudo Y, Yamamoto M, Inoue M, Okubo Y et al (2001). Relation among dopamine $\mathrm{D}(2)$ receptor binding, obesity and personality in normal human subjects. Neurosci Lett 300: 59-61.

Zanarini MC, Frankenburg FR (2001). Olanzapine treatment of female borderline personality disorder patients: a double blind, placebo-controlled pilot study. J Clin Psychiatry 62: 849-854.

Zanarini MC, Frankenburg FR, Dubo ED, Sickel AE, Trikha A, Levin A et al (1998). Axis I comorbidity of borderline personality disorder. Am J Psychiatry 155: 1733-1739. 